\title{
Assessment of Mycorrhizal Frequency in the Roots of Fruit Plants Using Different Dyes
}

\author{
Edyta Derkowska*, Lidia Sas Paszt, Barbara Dyki, Beata Sumorok \\ Research Institute of Horticulture, Skierniewice, Poland \\ Email: edyta.derkowska@inhort.pl
}

Received 2 January 2015; accepted 22 January 2015; published 29 January 2015

Copyright (C) 2015 by authors and Scientific Research Publishing Inc.

This work is licensed under the Creative Commons Attribution International License (CC BY). http://creativecommons.org/licenses/by/4.0/

c) (7) Open Access

\section{Abstract}

The aim of the experimental work was to optimize the previously used Phillips and Hayman (1970) method of staining roots for microscopic assessment of mycorrhizal frequency in the root material. The materials used in the experiment were the roots of strawberry plants of the cultivar "Elsanta" obtained in a greenhouse experiment in May 2012. Morphological features of the roots were assessed using a root scanner, and then attempts were made to stain the roots in four types of dyes: $0.01 \%$ methylene blue, $0.01 \%$ acridine orange, $0.01 \%$ malachite green, and $0.01 \%$ carbol fuchsin. A comparative microscopic assessment was made of the effects of staining with the four types of dyes the structures of mycorrhizal fungi formed in strawberry roots. Mycorrhizal frequency (F\%) in the stained root samples was also compared. Next, the usefulness of these dyes for staining the roots of other fruit plant species, such as apple, sweet cherry, blackcurrant and sour cherry, was evaluated. It was concluded that the staining of roots at a temperature of up to $65^{\circ} \mathrm{C} \mathrm{did} \mathrm{not} \mathrm{cause}$ tissue breakdown, and that the clearing time used-20 to 30 minutes, and the use of carbol fuchsin were found to be the most effective combinations in achieving good quality microscopic images. During microscopic examinations, a satisfactory contrast was noted between root tissues and the structures of mycorrhizal fungi. The use of carbol fuchsin for staining roots also helped to expose a greater number of fungal structures and obtain higher values of mycorrhizal frequency in the roots of strawberries, blackcurrants, sour cherries, sweet cherries and apples, in comparison with other dyes tested. The newly developed method of staining roots with carbol fuchsin, compared with the method used previously (Phillips and Hayman, 1970), is both less time consuming and less labour intensive.

\section{Keywords}

Staining Method, Roots, Mycorrhiza, Microscopic Assessment

\footnotetext{
${ }^{*}$ Corresponding author.
} 


\section{Introduction}

Mycorrhizal fungi play an important role in the succession and preservation of plant communities [1] [2]. The roots of higher plants are most often found to be living in symbiosis with arbuscular mycorrhizal fungi (AMF) [3]. The presence of these fungi in the soil can be an important element of sustainable agriculture [4]. Worldwide research shows that intensive soil cultivation reduces the diversity of mycorrhizal fungi in the soil [5]. Development and application of proper soil cultivation methods favour the development of soil microorganisms, including mycorrhizal fungi, which positively influence the growth and development of plants [4] [6] [7]. AM fungi can regulate water uptake from the soil or provide defence against pathogenic microbes and pests [8]. In the roots of plants, arbuscular mycorrhizal fungi can be seen in the form of mycelial hyphae, microscopic sacs called vesicles, and branched structures called arbuscules [9]. The arbuscules situated in the cells of roots are a place for the plant and fungus to exchange nutrients [8]. In order to learn the mechanisms and effects of the plant-fungus-rhizosphere interdependence for plant growth and development, it is important to correctly quantify the arbuscular mycorrhizal fungi colonizing root systems [10]. Non-destructive methods of visualizing AM fungi in roots have been developed, which are based on examinations of living roots with a conventional light microscope [11]. However, identification of the structures of mycorrhizal fungi and determination of mycorrhizal frequency using this technique are not very accurate because they are only based on the analysis of the thinnest, transparent roots with a small number of tissue layers [11]. Methods based on electron microscopy are very accurate, but in testing a large number of root samples, the possibility of employing such methods is limited by both the lack of widespread availability of this type of microscopes and the lengthy process of preparing the materials for mycorrhizal frequency analyses in laboratory conditions [11]. Methods for the visualization of mycorrhizal fungi in roots that have been developed as rapid tests with optimal staining of the material ensure the correctness of the microscopic assessment of the degree of colonization of roots by visualizing the structures present in the roots, such as arbuscules, vesicles, the mycelium and spores [12]. The staining method developed by Phillips and Hayman [13] has been modified by many authors [11] [14]-[17]. The method recommends staining with trypan blue and thermal maceration $\left(90^{\circ} \mathrm{C}\right)$ using $10 \%$ hydrochloric acid. It is a lengthy procedure (4 - 5 days), and when used, destruction of root cells can often be seen in microscopic images.

The aim of this study was to evaluate the usefulness of different dyes for staining roots in order to be able to assess mycorrhizal frequency more accurately and to better visualize the mycorrhizal structures in the roots of fruit plants.

\section{Materials and Methods}

Strawberry frigo plants of the cultivar "Elsanta" were planted in February 2012 in the Greenhouse Complex of the Research Institute of Horticulture in Skierniewice. The plants were planted in two-litre rhizoboxes, two per box. In May 2012, when the experiment was completed, four samples (50 g each) of the root system were collected from the control combination for a laboratory assessment of root growth characteristics. Then, on the basis of the results, in order to improve the method of staining, roots were selected with the best parameters, i.e. the largest root surface area and volume, and the largest number of root tips (Table 1).

\subsection{Determination of Root Growth Characteristics}

The root system obtained from the rhizoboxes was placed in a sieve and separated from soil particles by gently washing them off with a stream of water. After drying the roots on filter paper, they were scanned with an EPSON EXPRESSION 10000 XL root scanner. Root growth characteristics were determined using WinRhizo software [18] to measure: root length, root surface area, root diameter, root volume, and the number of root tips. Based on the results, roots from sample No. 1 were selected for further analyses because they had significantly higher root growth parameters compared with those of samples No. 2, 3 and 4 (Table 1).

\subsection{Staining Method Used Previously}

Staining of roots according to the previously used method of Phillips and Hayman [13] (as per [19]) lasted four days and was performed in the following stages:

1) Maceration and clearing of tissues with $10 \%$ potassium hydroxide $(\mathrm{KOH})-24 \mathrm{~h}$;

2) Elution of $\mathrm{KOH}$ with water-30 min; 
Table 1. Growth characteristics of the roots of strawberry plants in four $50 \mathrm{~g}$ samples.

\begin{tabular}{cccccc}
\hline $\begin{array}{c}\text { Sample No./root growth } \\
\text { characteristics }\end{array}$ & $\begin{array}{c}\text { Root length } \\
(\mathrm{cm} / 50 \mathrm{~g})\end{array}$ & $\begin{array}{c}\text { Root surface area } \\
\left(\mathrm{cm}^{2} / 50 \mathrm{~g}\right)\end{array}$ & $\begin{array}{c}\text { Root diameter } \\
(\mathrm{mm} / 50 \mathrm{~g})\end{array}$ & $\begin{array}{c}\text { Root volume } \\
\left(\mathrm{cm}^{3} / 50 \mathrm{~g}\right)\end{array}$ & $\begin{array}{c}\text { Number of root tips } \\
(\text { per } 50 \mathrm{~g})\end{array}$ \\
\hline 1 & $302.4 \mathrm{~d}$ & $169.8 \mathrm{c}$ & $2.49 \mathrm{~b}$ & $8.14 \mathrm{c}$ & $946 \mathrm{~d}$ \\
2 & $161.8 \mathrm{a}$ & $93.5 \mathrm{a}$ & $1.28 \mathrm{a}$ & $3.33 \mathrm{a}$ & $363 \mathrm{a}$ \\
3 & $210.6 \mathrm{c}$ & $132.3 \mathrm{ab}$ & $1.84 \mathrm{ab}$ & $5.22 \mathrm{~b}$ & $718 \mathrm{c}$ \\
4 & $199.1 \mathrm{ab}$ & $115.7 \mathrm{ab}$ & $1.62 \mathrm{ab}$ & $4.72 \mathrm{ab}$ & $412 \mathrm{~b}$ \\
\hline
\end{tabular}

Means in columns marked with the same letter do not differ at $p=0.05$ according to Tukey's multiple test.

3) Acidification with $5 \%$ lactic acid-24 h;

4) Staining in $0.01 \%$ aniline blue $-24 \mathrm{~h}$;

5) Washing with water to remove excess dye-30 min;

6) Preservation and storage of roots in $80 \%$ lactic acid.

\section{Results}

\subsection{Modification of the Staining Method to Shorten the Duration of Staining and Reduce Analysis Costs}

The improvement of the method consisted in the shortening of the duration of the staining of roots while preparing specimens for microscopic assessment of mycorrhizal frequency in the roots of fruit plants.

The following solutions were used to modify the staining method:

1) $10 \%$ sodium hydroxide;

2) $10 \%$ lactic acid;

3) Dyes: $0.01 \%$ methylene blue, $0.01 \%$ Acridine Orange, $0.01 \%$ malachite green and $0.01 \%$ carbol fuchsin.

To clear root tissues, a sodium hydroxide solution was used, which was poured over the roots; afterwards the roots were placed in a water bath for $20-30$ minutes at $65^{\circ} \mathrm{C}$. The use of a temperature higher than $80^{\circ} \mathrm{C}$ in this method resulted in severe destruction of tissues of the smallest strawberry roots. Next, the roots were washed under running tap water, dried and submerged in lactic acid for 10 minutes to bring the $\mathrm{pH}$ of the roots close to neutral $(\mathrm{pH})$. After that, the sample of roots was washed with distilled water and divided into four parts, with each having a different dye added to it. The effects of staining with the different dyes on the visualization of the structures of mycorrhizal fungi in the roots were assessed several times with a microscope. When choosing the dyes, consideration was given to the speed of penetration of the dye into the tissues of roots and the most suitable intensity of the colouration of mycorrhizal structures of different sizes and in different locations within the root tissues. The material thus prepared was used to make histological microscopic specimens by selecting 30 root fragments, each approx. $1 \mathrm{~cm}$ long. The root fragments were placed in glycerol, arranged parallel to one another, on a microscopic glass slide and then crushed with a coverslip. The specimens with the root fragments were examined using a Nikon 50i microscope (with $20 \times, 40 \times, 60 \times$ and $100 \times$ objectives). The quality of the microscopic images was assessed, taking mainly into account the possibility of an accurate and rapid assessment of roots in terms of the identification, number, size, and location of the stained mycorrhizal structures. Photographic records (Photos 1-12) of the microscopic images of the structures of mycorrhizal fungi in the roots of fruit plants were produced. Comparisons of the degree of colonization of the roots by arbuscular mycorrhizal fungi were made according to the method by Trouvelot [20]. The results were used to calculate mycorrhizal frequency $(\mathrm{F} \%)$ by means of a computer program called MYCOCALC, available from the website:

http://www2.dijon.inra.fr/mychintec/Mycocalc-prg/download.html (Table 2). The results for mycorrhizal frequency were compared with the data obtained using the previously used method of Phillips and Hayman [13], described above.

\subsection{Assessment of the Usefulness of the Modified Method for Staining the Roots of Apples, Sweet Cherries, Blackcurrants, and Sour Cherries}

On the basis of the quality of microscopic images of the structures of mycorrhizal fungi, which constituted the 
Table 2. Effect of the dyes used for staining roots on the values of mycorrhizal frequency $(\mathrm{F} \%)$ in the roots of fruit plants.

\begin{tabular}{cccccc}
\hline Type of dye/fruit plant species & Aniline blue & Methylene blue & Acridine orange & Malachite green & Carbol fuchsin \\
\hline strawberry & $20.0 \mathrm{a}$ & $20.0 \mathrm{a}$ & $33.33 \mathrm{bc}$ & $23.33 \mathrm{ab}$ & $38.89 \mathrm{c}$ \\
apple & $28.22 \mathrm{c}$ & $23.33 \mathrm{bc}$ & $12.22 \mathrm{a}$ & $20.0 \mathrm{ab}$ & $36.67 \mathrm{~d}$ \\
sweet cherry & $23.56 \mathrm{c}$ & $16.67 \mathrm{~b}$ & $13.33 \mathrm{a}$ & $13.33 \mathrm{a}$ & $28.89 \mathrm{~d}$ \\
blackcurrant & $20.22 \mathrm{c}$ & $13.33 \mathrm{~b}$ & $3.33 \mathrm{a}$ & $11.11 \mathrm{~b}$ & $26.67 \mathrm{~d}$ \\
sour cherry & $21.11 \mathrm{c}$ & $13.33 \mathrm{ab}$ & $11.11 \mathrm{a}$ & $12.22 \mathrm{ab}$ & $34.44 \mathrm{~d}$ \\
\hline
\end{tabular}

Means in columns marked with the same letter do not differ at $p=0.05$ according to Tukey's multiple test. Results compared separately for each species.

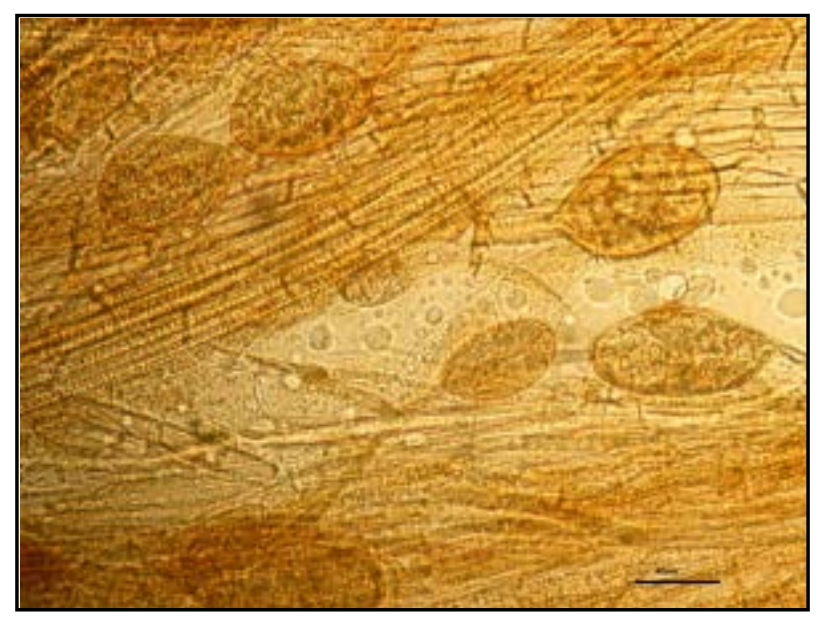

Photo 1. Barely visible vesicles in the roots of "Elsanta" strawberry plants stained with acridine orange.

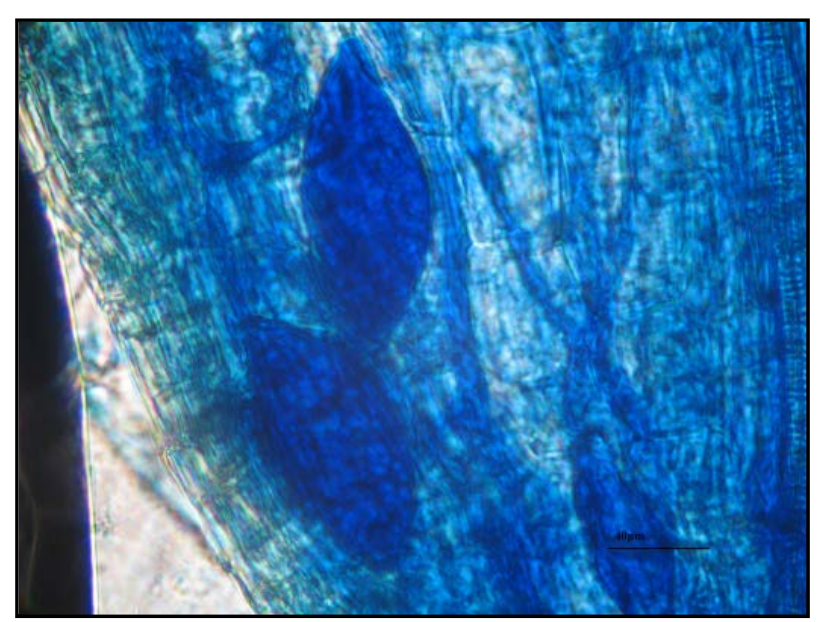

Photo 2. Barely visible vesicles in the roots of "Elsanta" strawberry plants stained with methylene blue.

results of the histological analyses of roots (Photos 1-4), carbol fuchsin was found to be the most effective dye, and thus useful for the visualization of mycorrhizal structures in the roots of fruit plants. Using this dye, it was possible to obtain not only the most pronounced staining of root tissues of various species of fruit plants but also the best and most accurate visualization of the structures of mycorrhizal fungi in the roots of these plants. Comparison of the microscopic images of root tissues of strawberry, apple, sweet cherry, blackcurrant, and sour 


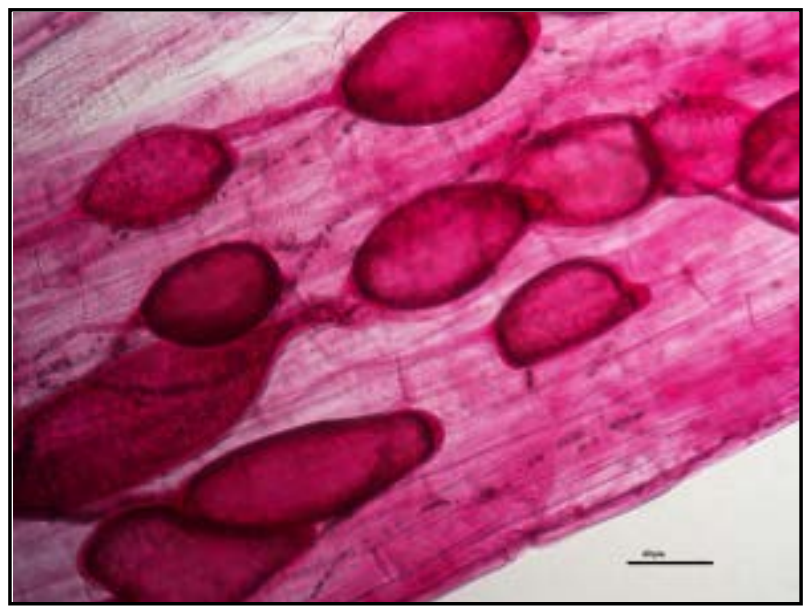

Photo 3. Highly visible and distinctly shaped vesicles in the roots of "Elsanta" strawberry plants stained with carbol fuchsin.

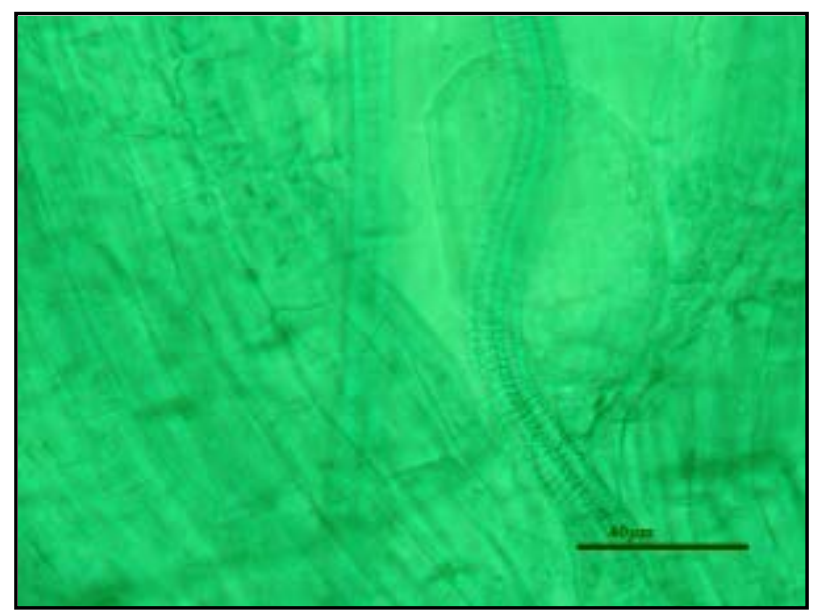

Photo 4. A hardly visible vesicle in the roots of "Elsanta" strawberry plants stained with green malachite.

cherry stained according to the Phillips and Hayman [13] method with the images of root tissues stained with carbol fuchsin made it possible to nominate this dye as the best for microscopic assessment of mycorrhizal frequency and visualization of the structures of mycorrhizal fungi in the roots of fruit plants.

\subsection{The New Method of Preparing and Staining Roots}

Steps of the method:

1) Maceration and clearing of root tissues with $10 \%$ sodium hydroxide $(\mathrm{NaOH})$ at $65^{\circ} \mathrm{C}-30 \mathrm{~min}$;

2) Washing out roots from $\mathrm{NaOH}$ solution with water- $-5 \mathrm{~min}$;

3) Acidification of roots with $10 \%$ lactic acid-10 min;

4) Washing out roots from lactic acid with distilled water- $5 \mathrm{~min}$;

5) Staining roots with carbol fuchsin-10 min;

6) Rinsing roots with water to remove excess dye $-10 \mathrm{~min}$;

7) Preservation and storage of roots in glycerol.

Root samples prepared in this way were analyzed using a Nikon 50i microscope (with $20 \times, 40 \times, 60 \times$ and $100 \times$ objectives). Assessment of the degree of root colonization by AM fungi was performed according to the method by Trouvelot [20], and on the basis of these results mycorrhizal frequency (F\%) was calculated using a computer program named MYCOCALC, available on the website: 
http://www2.dijon.inra.fr/mychintec/Mycocalc-prg/download.html (Table 2). The photographic records of the mycorrhizal structures observed in the roots stained with carbol fuchsin were compared with the images of the structures obtained from microscopic examinations according to the Phillips and Hayman [13] method. On the basis of the assessment of the quality of the images of microscopic mycorrhizal structures it was found that of all the dyes tested, staining roots with carbol fuchsin resulted in a significant increase in mycorrhizal frequency in the roots of strawberry, apple, sweet cherry, blackcurrant, and sour cherry (Table 2).

\subsection{Statistical Analysis}

The results were statistically analyzed using univariate analysis of variance in the system of random blocks. Multiple comparisons of the means for the combinations were performed with Tukey's test at a significance level of $\alpha=0.05$ using STATISTICA v.10 software package [StatSoft, Inc., 2011].

\section{Discussion}

Data from world literature indicate that many authors have attempted to modify the staining method developed by Phillips and Hayman in 1970 [13]. The dyes used for staining roots have also been evaluated in terms of their toxicity and effects on human health [16]. However, most of the modified methods still rely on the use of high temperatures $\left(80^{\circ} \mathrm{C}-121^{\circ} \mathrm{C}\right)$, or involve a several-hour process of staining roots.

By using carbol fuchsin for staining roots, the duration of staining was shortened to one hour and ten minutes, compared with four days required by the previously used method. The applied temperature of $65^{\circ} \mathrm{C}$ did not impair the structure of the stained roots, nor the quality of the microscopic specimens. The results for mycorrhizal frequency in the roots of strawberry, apple, sweet cherry, blackcurrant, and sour cherry indicate greater accuracy and greater usefulness of the newly developed method of staining roots, compared with the results obtained using the method developed by Phillips and Hayman [13]. The highest mycorrhizal frequency was recorded in the roots of fruit plants stained with carbol fuchsin, and significantly lower in the roots stained with aniline blue as standard and the other dyes (Table 2). Staining roots with methylene blue, acridine orange, or green malachite resulted in significantly lower values of mycorrhizal frequency than under the influence of carbol fuchsin and in inferior visualization of the mycorrhizal structures in the roots of fruit plants (Photos 1-4). Staining roots with carbol fuchsin resulted in the best and clearest visualization of mycorrhizal structures (Photo 3). The mycorrhizal structures were highly visible and their contrasting outline against a background of root tissues made it easier to identify them and thus helped to make a more accurate assessment of mycorrhizal frequency. The use of carbol fuchsin for staining plant roots also made it possible to reduce analysis time and cost. It should be emphasized that storage of root specimens stained with carbol fuchsin, even for a period of four months at room temperature, did not impair the quality of microscopic images. For these reasons, carbol fuchsin was nominated as the best dye for staining roots to assess mycorrhizal frequency in the roots of strawberry, apple, sweet cherry, blackcurrant, and sour cherry plants. Very good visualization of mycorrhizal structures in the root specimens prepared using the newly developed method made it possible to produce very good photographic records (Photos 5-12). The results of the assessment were more accurate: by $94.5 \%$ in strawberry, $63.2 \%$ in sour cherry, $31.9 \%$ in blackcurrant, $29.9 \%$ in apple, and $22.6 \%$ in sweet cherry (Table 3 ). Already more than half a century ago, Carmichael [21] used acid fuchsin to stain roots, using in the process a low-temperature range $\left(47^{\circ} \mathrm{C}-68^{\circ} \mathrm{C}\right)$. However, the staining process lasted several hours (about $6 \mathrm{~h}$ ) and the material obtained for microscopic analyses was not always of high quality (high percentage of poorly stained roots). Phillips and Hayman [13] developed a staining process based on trypan blue, which lasted from 3 days (hot staining at $90^{\circ} \mathrm{C}$ ) to $4-5$ days (cold staining). Hot staining had a destructive effect on root tissues as a result of using a high temperature $\left(90^{\circ} \mathrm{C}\right)$. Brundrett $\mathrm{et} \mathrm{al}$. [14] conducted research on the modification of the method of staining roots developed by Phillips and Hayman [13] by comparing dyes such as trypan blue, aniline blue, acid fuchsin and chlorazol black, and using staining temperatures from $90^{\circ} \mathrm{C}$ to $120^{\circ} \mathrm{C}$. They found that the best results were obtained by staining roots with trypan blue, as the roots stained with acid fuchsin were characterized by a low intensity of colouring of root tissues and mycorrhizal structures, and the dye itself quickly faded. Different results were obtained by the authors of this study. Among the dyes used, the best results were achieved by staining roots with carbol fuchsin; visualization of mycorrhizal structures was most favourable for assessing mycorrhizal frequency. The roots were the most intensely stained and the dye remained in the root tissues for four months after the preparation of microscopic specimens. McGonigle et al. [22] developed a method based on counting various mycorrhizal structures present 
Table 3. Comparison of mycorrhizal frequency in the roots of fruit plants stained with aniline blue and carbol fuchsin (\%).

\begin{tabular}{ccc}
\hline Fruit plant species & Aniline blue & Carbol fuchsin \\
\hline strawberry & $100 \% \mathrm{a}$ & $194.5 \% \mathrm{~b}$ \\
apple & $100 \% \mathrm{a}$ & $129.9 \% \mathrm{~b}$ \\
sweet cherry & $100 \% \mathrm{a}$ & $122.6 \% \mathrm{~b}$ \\
blackcurrant & $100 \% \mathrm{a}$ & $131.9 \% \mathrm{~b}$ \\
\hline
\end{tabular}

Means in columns marked with the same letter do not differ at $p=0.05$ according to Tukey's multiple test. Results compared separately for each species.

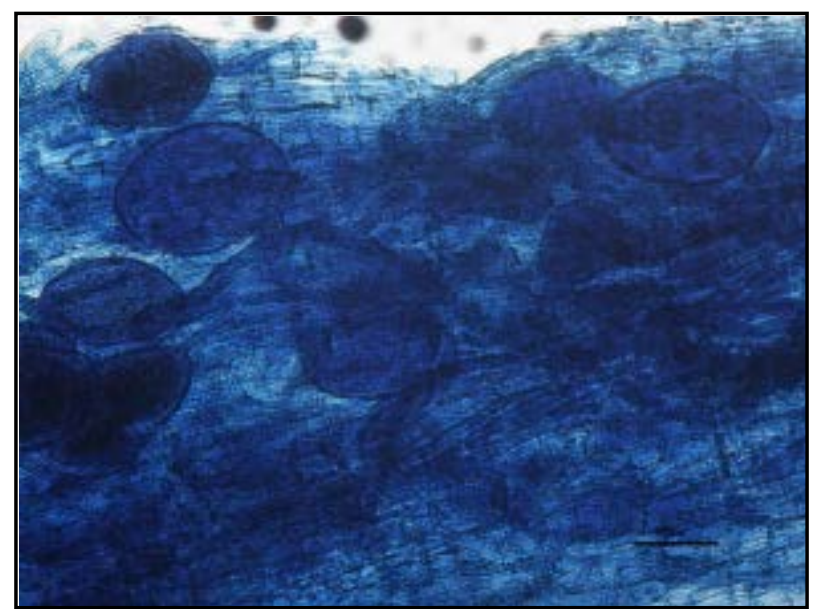

Photo 5. Vesicles in the roots of "Gold Milenium" apple trees stained with aniline blue.

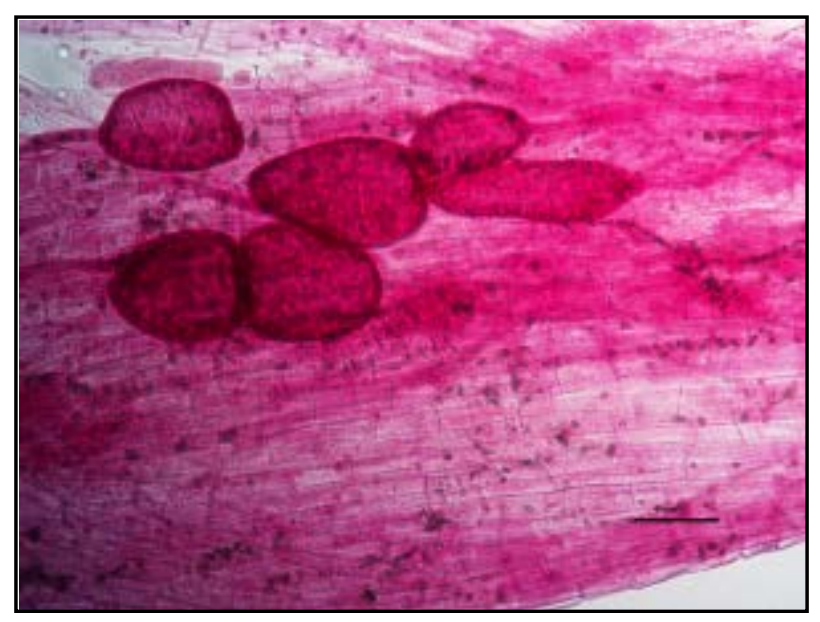

Photo 6. Vesicles in the roots of "Gold Milenium" apple trees stained with carbol fuchsin.

in roots using a stereoscopic microscope. They used Chlorazol Black E for staining, and the roots were treated at $121^{\circ} \mathrm{C}$. They obtained satisfactory results of microscopic analyses of the stained mycorrhizal structures, but only the thinnest roots were suitable for microscopic examinations because the magnifications used did not allow accurate examinations of thicker roots. It should be emphasized that microscopic examinations require the person performing the analysis to have a lot of experience in identifying structures of mycorrhizal fungi, with particular regard to the knowledge of the structure and function of the tissues of the roots of different plant species. This 


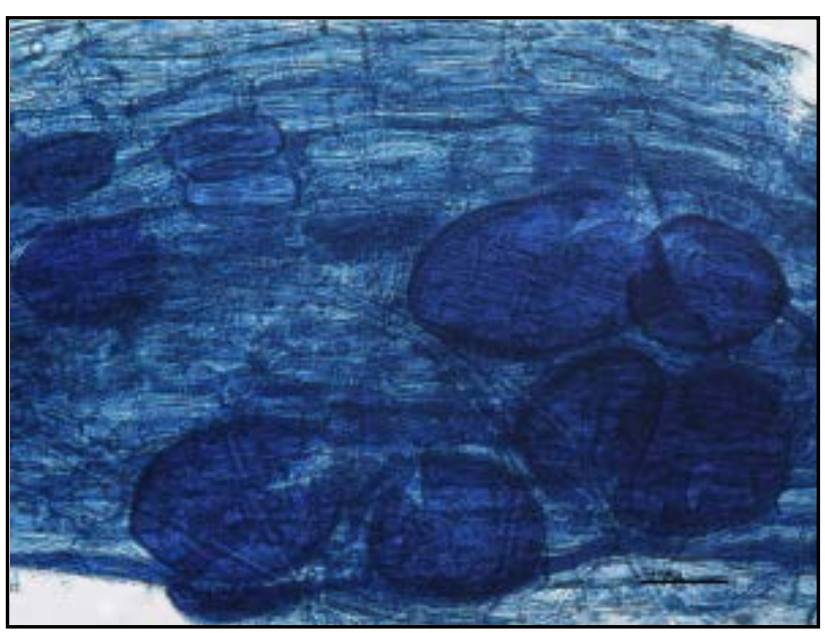

Photo 7. Vesicles in the roots of "Vanda" sweet cherry trees stained with aniline blue.

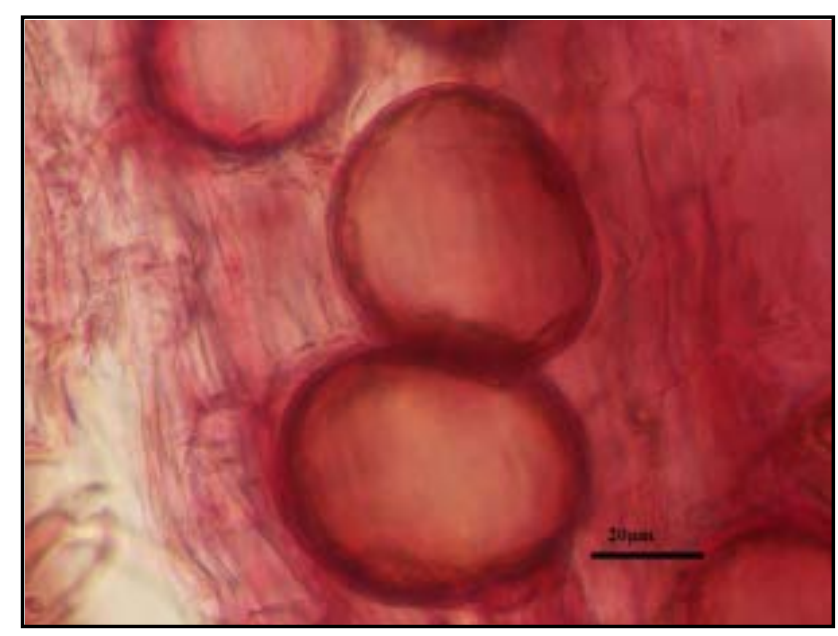

Photo 8. Vesicles in the roots of "Vanda" sweet cherry trees stained with carbol fuchsin.

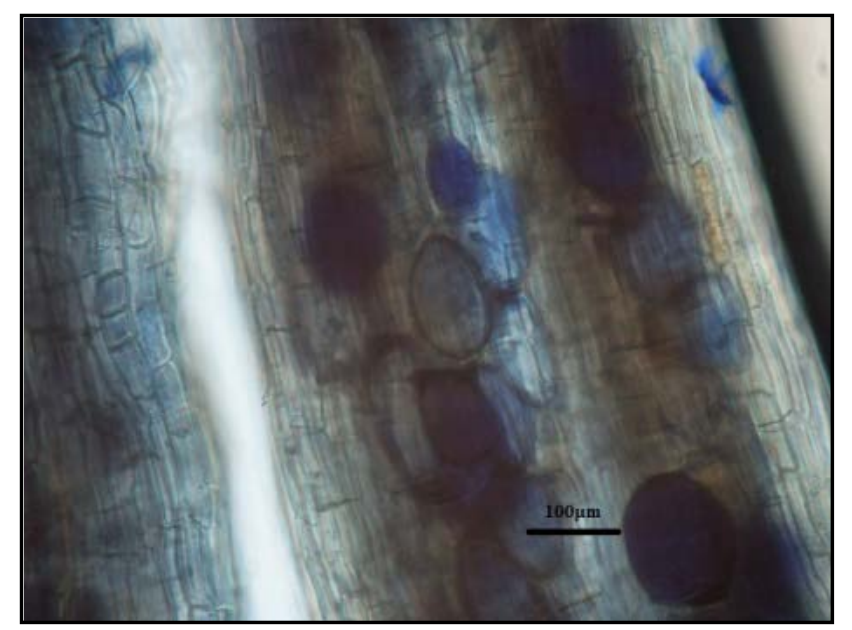

Photo 9. Vesicles in the roots of "Tiben" blackcurrant shrubs stained with aniline blue. 


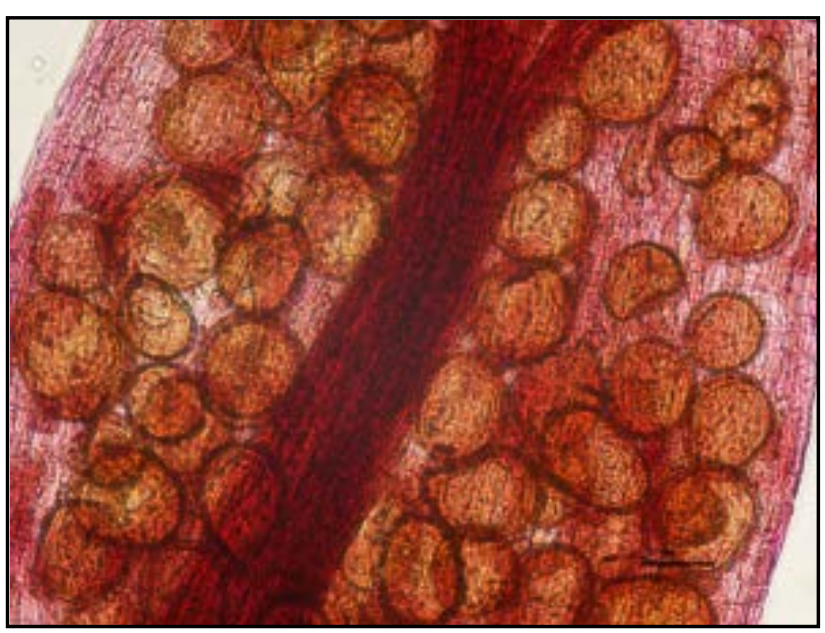

Photo 10. Vesicles in the roots of "Tiben" blackcurrant shrubs stained with carbol fuchsin.

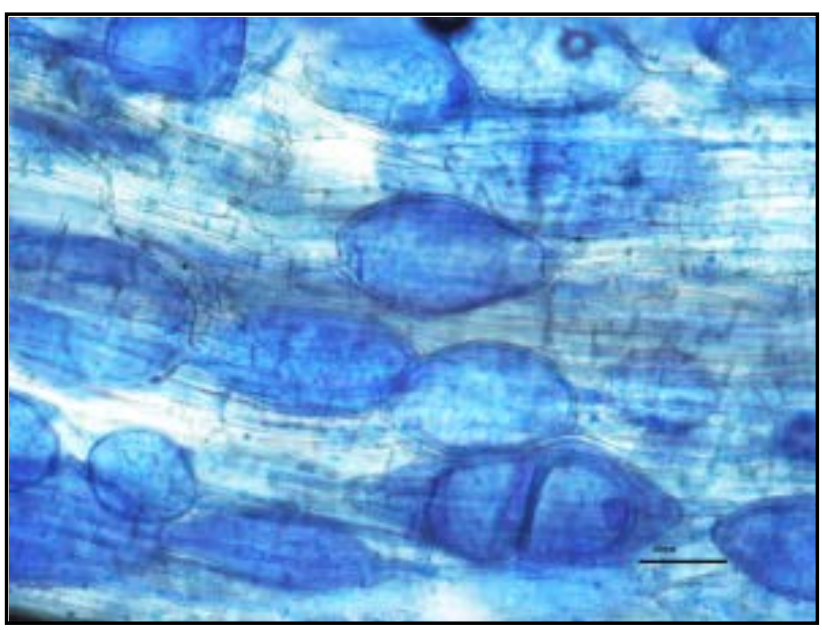

Photo 11. Vesicles in the roots of "Sabina" sour cherry trees stained with aniline blue.

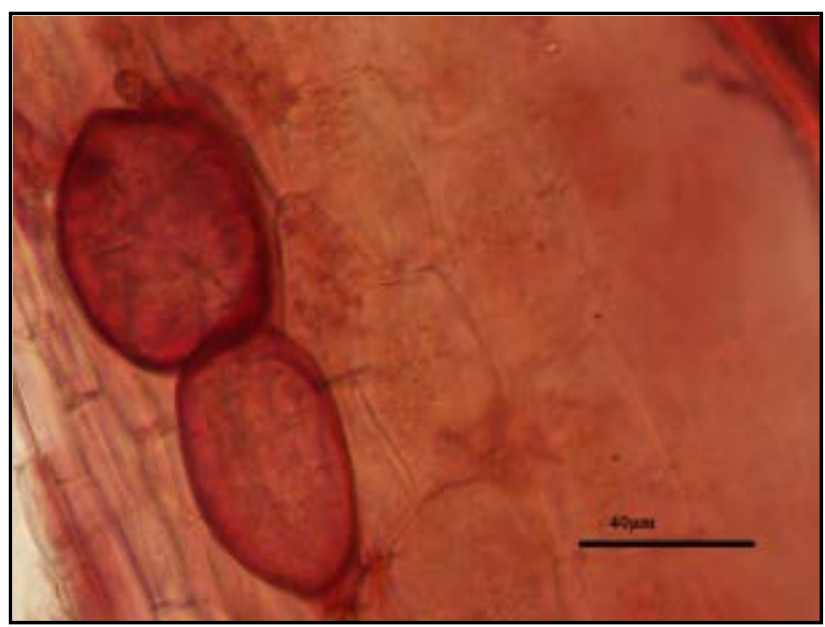

Photo 12. Vesicles in the roots of "Sabina" sour cherry trees stained with carbon fuchsin. 
knowledge enables a precise analysis and helps to eliminate from the assessment other species of fungi that can colonize the roots and are visible in the microscopic images of mycorrhizal structures. Vierheilig et al. [16] proposed to stain roots with five colours of ink; to destain the roots, they used a solution of acetic acid. Their staining procedure involved the use of very high temperatures of up to about $100^{\circ} \mathrm{C}$. They found that the best results could be obtained by staining with a black ink and acetic acid. Mycorrhizal structures were clearly visible after the staining process as well as after six weeks of storing the specimens in tap water. Dalpé and Séguin [10] studied the effect of treating roots with microwaves on the duration of the staining process and its quality, and the preservation of the integrity of DNA for further molecular analyses. They subjected roots treated with trypan blue, aniline blue and acid fuchsin to a short exposure to microwaves ( 30 seconds - 1.5 minutes). They found that trypan blue and acid fuchsin produced the most favourable effects on the visualization of structures in the roots. Results of many authors indicate a destructive effect on roots of the high temperatures used during the staining of the roots of fruit plants, especially those of strawberry. In the experiments by the authors of this paper, root tissues already disintegrated upon treatment for a few minutes at a temperature above $80^{\circ} \mathrm{C}$. The use of a lower temperature $\left(65^{\circ} \mathrm{C}\right)$ and a shorter time for it to act on the roots $(30 \mathrm{~min}$.) was favourable to the visualization of mycorrhizal structures and greatly facilitated the assessment of the degree of mycorrhizal association in the roots. The shortening of the staining time to one hour and ten minutes, compared with other staining methods (6 h-Carmichael [21], and 4 - 5 days-Phillips and Hayman [13]), will allow a larger number of samples to be prepared in a shorter period of time, which in turn will reduce the storage time of the material for analyses and significantly increase the likelihood of confirmation of the presence and identification of the structures of mycorrhizal fungi in the roots of plants.

The results of this study indicate that the newly developed method for staining roots using carbol fuchsin can be useful for staining the roots of fruit plants for microscopic assessment of the colonization of roots by mycorrhizal fungi. For a large number of collected root samples, the use of the new method of staining roots allows shortening of the duration of analysis and storage of the material before microscopic assessment. During the growing season, when assessing a large number of root samples from plants growing in greenhouse and field experiments, the new method allows a rapid and more accurate assessment of mycorrhizal frequency and better visualization of mycorrhizal structures in the roots of plants. The main advantages of the method developed by the authors of this study are a significant increase in the ability to accurately determine mycorrhizal frequency in the roots of fruit plants and a significant saving of time and effort.

\section{Conclusions}

1) The newly developed method for staining roots using carbol fuchsin increased the likelihood of correctly identifying the structures of mycorrhizal fungi in the roots of the fruit plant species studied;

2) Compared with the standard method, the new method of staining roots increased the values of mycorrhizal frequency in the roots of strawberries, apples, sweet cherries, blackcurrants, and sour cherry plants;

3) The new method of staining roots using carbol fuchsin allows a greater number of samples to be prepared in a shorter period of time, without the need for long-term storage, which increases the economic efficiency of the analyses performed.

This publication is part of the project "Development of Innovative Products and Technologies for Organic Cultivation of Fruit Plants" with an acronym EkoTechProdukt, co-financed by the European Regional Development Fund, Innovative Economy Operational Programme 2007-2013, Sub-Measure 1.3.1 OP IE.

\section{References}

[1] Brundrett, M.C. (1991) Mycorrhizas in Natural Ecosystems. Advances in Ecological Research, 21, 171-313. http://dx.doi.org/10.1016/S0065-2504(08)60099-9

[2] Allen, M.F. (1991) The Ecology of Mycorrhizae. Cambridge University Press, Cambridge.

[3] Li, X.L. and Feng, G. (2001) Ecophysiology of Arbuscular Mycorrhizas. Huawen Press, Beijing.

[4] Gianinazzi, S., Gollotte, A., Binet, M.N., van Tuinen, D., Redecker, D. and Wipf, D. (2010) Agroecology: The Key Role of Arbuscular Mycorrhizas in Ecosystem Services. Mycorrhiza, 20, 519-530. http://dx.doi.org/10.1007/s00572-010-0333-3

[5] Oehl, F., Sieverding, E., Ineichen, K., Mäder, P., Boller, T. and Wiemken, A. (2003) Impact of Land Use Intensity on the Species Diversity of Arbuscular Mycorrhizal Fungi in Agroecosystems of Central Europe. Applied and Environmental 
Microbiology, 69, 2816-2824. http://dx.doi.org/10.1128/AEM.69.5.2816-2824.2003

[6] Cameron, D.D. (2010) Arbuscular Mycorrhizal Fungi as (Agro) Ecosystem Engineers. Plant and Soil, $333,1-5$. http://dx.doi.org/10.1007/s11104-010-0361-y

[7] Raviv, M. (2010) The Use of Mycorrhiza in Organically-Grown Crops under Semi arid Conditions: A Review of Benefits, Constraints and Future Challenges. Symbiosis, 52, 65-74. http://dx.doi.org/10.1007/s13199-010-0089-8

[8] Smith, S.E. and Read, D.J. (2008) Mycorrhizal Symbiosis. 3rd Edition, Academic Press, London.

[9] Głuszek, S., Sas Paszt, L., Sumorok, B. and Derkowska, E. (2008) Wpływ mikoryzy na wzrost i plonowanie roślin ogrodniczych. Postępy Nauk Rolniczych, Warszawa, 11-22.

[10] Dalpé, Y. and Séguin, S.M. (2013) Microwave-Assisted Technology for the Clearing and Staining of Arbuscular Mycorrhizal Fungi in Roots. Mycorrhiza, 23, 333-340. http://dx.doi.org/10.1007/s00572-012-0472-9

[11] Vierheilig, H., Schweiger, P. and Brundrett, M. (2005) An Overview of Methods for the Detection and Observation of Arbuscular Mycorrhizal Fungi in Roots. Physiologia Plantarum, 125, 393-404.

[12] Brundrett, M.C. (2004) Diversity and Classification of Mycorrhizal Associations. Biological Reviews, 78, $473-495$. http://dx.doi.org/10.1017/S1464793103006316

[13] Phillips, J.M. and Hayman, D.A. (1970) Improved Procedures for Clearing Roots and Staining Parasitic and Vesicular-Arbuscular Mycorrhizal Fungi for Rapid Assessment of Infection. Transactions of the British Mycological Society, 55, 158-161. http://dx.doi.org/10.1016/S0007-1536(70)80110-3

[14] Brundrett, M.C., Piché, Y. and Peterson, R.L. (1984) A New Method for Observing the Morphology of Vesicular-Arbuscular Mycorrhizae. Canadian Journal of Botany, 62, 2128-2134.

[15] Schaffer, G.F. and Peterson, R.L. (1993) Modifications to Clearing Methods Used in Combination with Vital Staining of Roots Colonized with Vesicular-Arbuscular Mycorrhizal Fungi. Mycorrhiza, 4, 29-35. http://dx.doi.org/10.1007/BF00203248

[16] Vierheilig, H., Coughlan, A.P., Wyss, U. and Piche, Y. (1998) Ink and Vinegar, a Simple Staining Technique for Arbuscular-Mycorrhizal Fungi. Applied and Environmental Microbiology, 64, 5004-5007.

[17] Pitet, M., Camprubi, C., Calvet, C. and Estaun, V. (2009) A Modified Staining Technique for Arbuscular Mycorrhizal Compatible with Molecular Probes. Mycorrhiza, 19, 125-131. http://dx.doi.org/10.1007/s00572-008-0206-1

[18] Arsenault, J.L., Poulcur, S., Messier, C. and Guay, R. (1995) WIN-RHIZO a Root-Measuring System with a Unique Overlap Correction Method. HortScience, 30, 906.

[19] Turnau, K., Ryszka, P., Tuinen van, D. and Gianinazzi-Pearson, V. (2001) Identification of Arbuscular Mycorrhizal Fungi in Soils and Roots of Plants Colonizing Zinc Wastes in Southern Poland. Mycorrhiza, 10, 169-174. http://dx.doi.org/10.1007/s005720000073

[20] Trouvelot, A., Kough, J.L. and Gianinazzi-Pearson, V. (1986) Mesure du taux de mycorhization VA d'un systeme radiculaire. Recherche de methods d'estimation ayant une signification fonctionnelle. In: Gianinazzi-Pearson V. and Gianinazzi, S., Eds, Physiological and Genetical Aspects of Mycorrhizae, INRA, Paris, 217-221.

[21] Carmichael, J.W. (1955) Lacto-Fuchsin a New Medium for Mounting Fungi. Mycologia, 47, 611.

[22] McGonigle, T.P., Miller, M.H., Evans, D.G., Fairchild, G.L. and Swan, J.A. (1990) A New Method Which Gives an Objective Measure of Colonization of Roots by Vesicular-Arbuscular Mycorrhizal Fungi. New Phytologist, 115, 495501. http://dx.doi.org/10.1111/j.1469-8137.1990.tb00476.x 
Scientific Research Publishing (SCIRP) is one of the largest Open Access journal publishers. It is currently publishing more than 200 open access, online, peer-reviewed journals covering a wide range of academic disciplines. SCIRP serves the worldwide academic communities and contributes to the progress and application of science with its publication.

Other selected journals from SCIRP are listed as below. Submit your manuscript to us via either submit@scirp.org or Online Submission Portal.
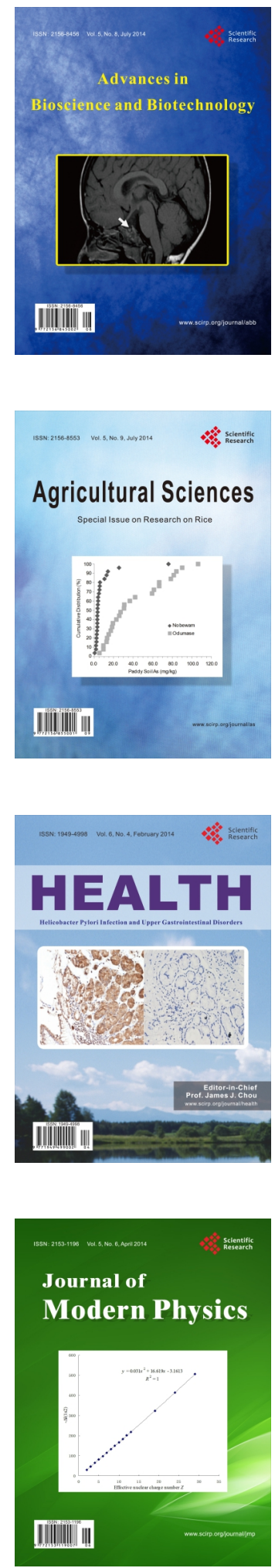
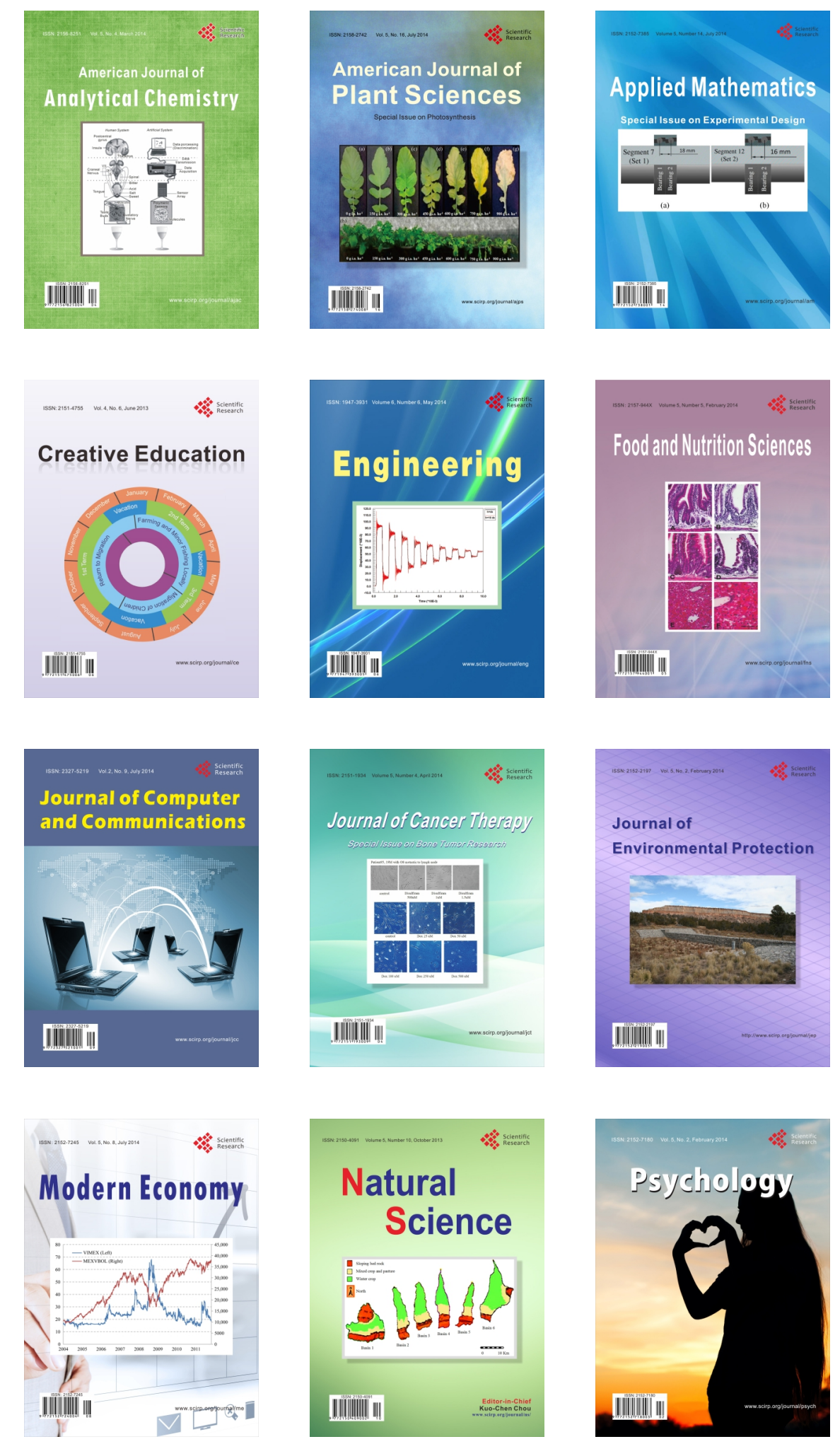